\title{
Solo Trial arena dengan Pendekatan Arsitektur METAFORA
}

\author{
Hendryk Trisnanto, Wiwik Setyaningsih, Rachmadi Nugroho \\ Program Studi Arsitektur \\ Jurusan Arsitektur Fakultas Teknik \\ Universitas Sebelas Maret Surakarta \\ Email : hnd.trisnant@yahoo.com
}

\begin{abstract}
Solo Trial Arena motivated by the many communities in Solo Trial, yet the presence of the gym, as well as the necessary infrastructure for fans of the trial, so the purpose of this scheme is to get a building design that can facilitate trial activities, facilitate community events and exhibitions Trial in building form that expresses the shape and dynamic motion of a motorcycle in the city of Solo. The issue of the design are: how the expression shape and dynamic motion of the motor can be translated into the design of the container Solo Trial Arena. The method used is the method of architectural design. The result obtained is the design of a trial arena, community center and exhibition center trial in a building that expresses in a concrete form of motorcycle parts and in the abstract with the philosophy of the dynamic motion of a motorcycle so that the building can reflect the activity in it
\end{abstract}

Keywords: Building Aesthetic, Metafora Architecture, Structural Aspects, Trial Arena.

\section{PENDAHULUAN}

Olahraga trial adalah kegiatan positif buat berbagai kalangan dan sudah menjadi fenomena di setiap kota, namun belum ada wadah yang memfasilitasi segala kegiatan yang berhubungan dengan olahraga trial. Saat ini kegiatan petualangan motor mulai kehilangan lahan bermain akibat banyak penduduk yang sudah mengkomersialkan jalanan kampung mereka bagi kegiatan petualangan motor khususnya trial ini.

Tempat ini direncanakan dapat mewadahi para pecinta trial dalam berkumpul, memperoleh pengetahuan, aksesori, dan bisa melakukan kegiatan dengan fasilitas yang layak dan mencukupi. Pemain trial di lndonesia di harapkan semakin bisa bersaing dalam tingkat nasional, Asia maupun internasional.

\section{METODE}

Solo Trial Arena adalah suatu tempat berupa bangunan dan area luar ruangan yang memfasilitasi penggemar olahraga petualangan motor khususnya trial di Surakarta dan sekitarnya termasuk mewadahi organisasi, komunitas, tempat latihan, maupun kompetisikompetisi yang ada. Kendala wadah kegiatan trial adalah bagaimana menentukan konsep penampilan bangunan, tata ruang, maupun kawasannya. Solo Trial Arena menggunakan pendekatan Arsitektur Metafora dengan mengumpamakan sesuatu menjadi bentuk pada penampilan bangunan, tata ruang, maupun kawasannya sehingga dapat menciptakan bentuk bangunan yang kreatif, memicu kepuasan batin, dan menarik.

\section{ANALISIS}

\subsection{Analisis Peruangan}

Analisa peruangan diperoleh dari analisa kegiatan pengguna bangunan. Persyaratan ruang dalam hal ini membahas tentang kebutuhan kenyamanan untuk sebuah ruang. Dasar pertimbangan dari penentuan kenyamanan sebuah ruang didasarkan dari kenyamanan penghawaan, kenyamanan pencahayaan dan pengendalian bising. Penataan organisasi ruang yang baik memerlukan perancanaan yang matang agar menjadi tepat guna. Adapun kebutuhan ruang bangunan yang direncanakan adalah sebagai berikut (lihat Tabel 1).

Tabel 1.Kebutuhan Ruang

\begin{tabular}{|l|l|l|}
\hline PELAKU & KEGIATAN & $\begin{array}{l}\text { PERUANGA } \\
\mathrm{N}\end{array}$ \\
\hline Penonton & Datang & Hall \\
\hline
\end{tabular}




\begin{tabular}{|l|l|l|}
\hline \multirow{4}{*}{} & & penerima \\
\cline { 2 - 3 } & Membeli karcis & $\begin{array}{l}\text { R. Loket } \\
\text { pembelian }\end{array}$ \\
\cline { 2 - 3 } & Memeriksa karcis & R. Cek karcis \\
\cline { 2 - 3 } & Menonton & Tribun \\
\hline Atlet & Datang & $\begin{array}{l}\text { Hall } \\
\text { penerima }\end{array}$ \\
\cline { 2 - 3 } & Persiapan & $\begin{array}{l}\text { R. } \\
\text { Ganti/loker }\end{array}$ \\
\cline { 2 - 3 } & Pemanasan & $\begin{array}{l}\text { R. } \\
\text { Pemanasan }\end{array}$ \\
\cline { 2 - 3 } & $\begin{array}{l}\text { Berlatih/bertandin } \\
\text { g }\end{array}$ & Arena trial \\
\hline pengelola & Datang & $\begin{array}{l}\text { Hall } \\
\text { penerima }\end{array}$ \\
\cline { 2 - 3 } & Persiapan & $\begin{array}{l}\text { R.Ganti/loke } \\
\text { r. }\end{array}$ \\
\cline { 2 - 3 } & Kantor dan Rapat & R.Pengelola \\
\hline Pers & Datang & $\begin{array}{l}\text { Hall } \\
\text { penerima }\end{array}$ \\
\cline { 2 - 3 } & $\begin{array}{l}\text { Meliput } \\
\text { pertandingan }\end{array}$ & Arena trial \\
\hline
\end{tabular}

\subsection{Analisis Lokasi}

Selain menentukan lokasi yang strategis, memilih tapak dengan kondisi yang mendukung keberadaan arena trial ini sangat menentukan prospek bangunan tersebut.

1. Tujuan

Mendapatkan lokasi yang sesuai dengan keberadaan arena.

2. Dasar pertimbangan:

Posisi tapak strategis untuk menampilan fisik bangunan, luasan tapak dapat menampung seluruh kebutuhan ruang yang direncanakan.

3. Proses Analisis

Terdapat 4 alternatif dalam pemilihan lokasi tapak yaitu Asrama Polri Manahan, Kawasan Kota Barat, Kawasan Gendengan, dan Kawasan Mojosongo. Kawasan Mojosongo dipilih karena mencukupi dalam segala pertimbangan yang ada.

\subsection{Analisis Pencapaian}

Pencapaian ke dalam bangunan harus mudah diakses, mudah dilihat dan memiliki sirkulasi yang aman akan menstimulus orang untuk masuk dalam area bangunan. Dalam pencapaian ke dalam bangunan juga harus terlihat dengan jelas untuk sirkulasi kendaraan yg akan masuk.

1. Tujuan: menentukan main entrane, menentukan service entrance

2. Dasar Pertimbangan: kemudahan akses, sirkulasi tapak yang aksesibel, arus kendaraan dan potensi jalan, tingkat keamanan.

3. Proses analisis

\section{Main Entrance (ME)}

Mudah dijangkau dan terlihat dengan jelas. Menghadap langsung ke arah jalan untuk kemudahan sirkulasi kendaraan masuk dan ke luar tapak. Pintu masuk dalam bangunan dipilih pada bagian depan bangunan yang menghadap langsung ke jalan untuk kelancaran sirkulasi kendaraan.

\section{Side Entrance (SE)}

Tidak mengganggu keberadaan ME sehingga membantu sirkulasi pengunjung terutama sebelum atau pun sesudah pertandingan seperti pada Gambar 1 .

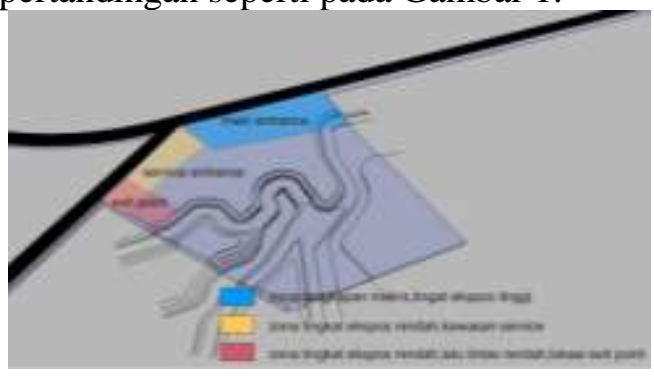

Gambar 1. Pola Pencapaian

\subsection{Analisis Pemintakatan (Penzoningan)}

Pemintakatan berdasarkan sifat kegiatan dan keadaan dalam tapak dilakukan sebagai acuan dalam penataan peruangan, namun tetap memperhatikan modul-modul struktur yang telah diterapkan.

1. Tujuan: Menentukan mintakat (zoning) berdasarkan sifat kegiatan dan keadaan pada tapak.

2. Dasar pertimbangan: analisis peruangan, analisis pengolahan tapak, analisis struktur.

3. Proses analisis: persyaratan ruang, berdasarkan kelompok kegiatan dan analisis pengolahan tapak seperti pada Tabel 2.

Tabel 2. Persyaratan Ruang

\begin{tabular}{|c|c|c|c|}
\hline $\begin{array}{c}\text { MINTA } \\
\text { KAT }\end{array}$ & KEL. & PERSYAR & IMPLIK \\
RUANG & ATAN & ASI \\
\hline
\end{tabular}




\begin{tabular}{|c|c|c|c|}
\hline$($ ZONING) & & & $\begin{array}{c}\text { STRUK } \\
\text { TUR }\end{array}$ \\
\hline Publik & Penerima & \begin{tabular}{|l|} 
Pencapaian \\
mudah \\
View from/to \\
site menjadi \\
pertimbangan \\
utama \\
Pencahayaan \\
dan \\
penghawaan \\
alami penting
\end{tabular} & $\begin{array}{l}\text { struktur } \\
\text { harus } \\
\text { terlihat } \\
\text { jelas } \\
\text { Berada } \\
\text { pada } \\
\text { bentang } \\
\text { struktur } \\
\text { yang } \\
\text { cukup } \\
\text { lebar }\end{array}$ \\
\hline Semi publik & Pendidikan & \begin{tabular}{|l|} 
Pencapaian \\
telihat \\
Noise penting \\
Pencahayaan \\
dan \\
penghawaan \\
alami + buatan
\end{tabular} & $\begin{array}{l}\text { Area } \\
\text { luar } \\
\text { ruangan } \\
\text { disesuai } \\
\text { kan } \\
\text { dengan } \\
\text { modul } \\
\text { struktur }\end{array}$ \\
\hline
\end{tabular}

\subsection{Analisis Bentuk dan Tampilan}

\section{Bangunan}

\subsubsection{Analisis Bentuk Bangunan}

Citra pada tampilan bangunan diambil dari perencanaan sepak bola yang direncanakan menggunakan 5 prinsip yang mengadopsi dari DK. Ching (1979), tentang prinsip dasar mendesain Solo Trial Arena, selain itu prinsip tersebut dapat dikorelasikan dengan teori struktur sebagai ornamen.

\subsubsection{Konsep Tata Massa}

Susunan massa pada tapak berkisar pada bentuk kubus dengan variasi dan pengembangannya, mengacu pada pendekatan Arsitektur Metafora yaitu perumpamaan dari bentuk dinamis sebuah motor trial dan sebuah pengembangan halang rintang yang merupakan bagian dari olahraga trial itu sendiri baik yang diterapkan di luar bangunan maupun di dalam suatu bangunan ditunjukkan pada Gambar 2.

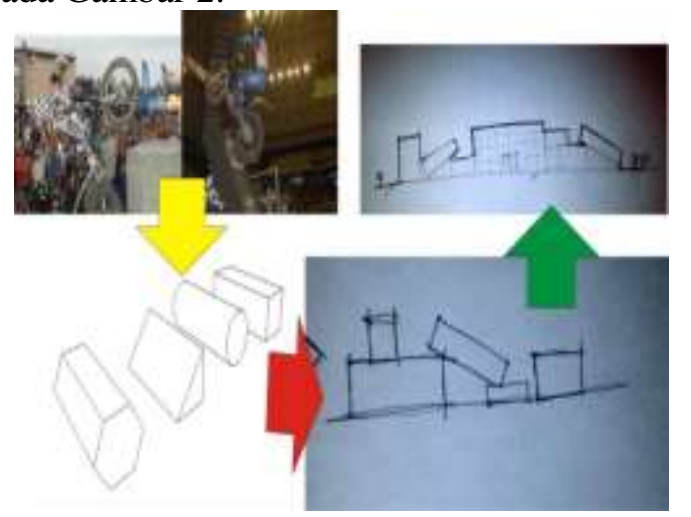

Gambar 2. Tata Masa

\subsubsection{Konsep Tampilan Bangunan}

Perubahan bentuk kotak kotak akan diaplikasikan pada massa utama bangunan Solo Trial Arena yang seakan-akan sebagai pendukung perumpamaan dari rintangan terhadap massa lainnya seperti pada Gambar 3.

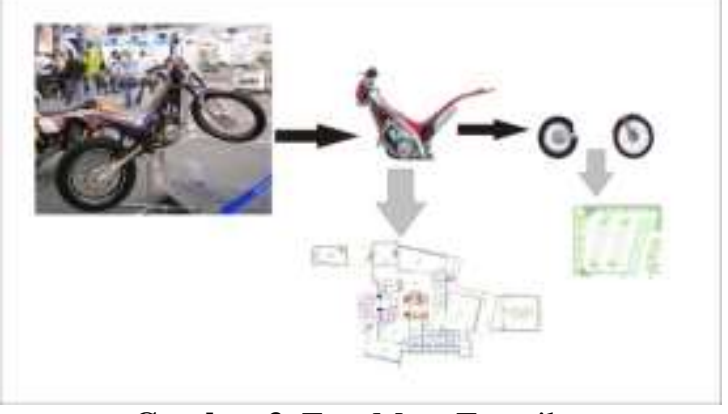

Gambar 3. Tata Masa Tampilan

\subsubsection{Konsep Bentuk Massa Bangunan Utama \\ Massa bangunan utama merupakan} bentuk kubus dibuat melengkung yang merupakan perwujudan dari bentuk lekuk rintangan dalam trial sebagai pendukung pendekatan Arsitektur Metafora dari perwujudan gerakan melompat dan keseimbangan terhadap massa gedung utama Solo Trial Arena.

\subsection{Analisa Ruang-Ruang Khusus}

Rintangan untuk trial ini menggunakan bahan kayu, besi, dan aslinya (batu, pohon). Rintangan-rintangan ini dibuat untuk bisa dibongkar pasang dan dibuat secara permanen. Selain bentuk-bentuk halang rintang standart yang akan digunakan untuk Solo Trial Arena ini juga menggunakan rintangan-rintangan dengan cekungan yang bahaya sesuai kaidah metafora gerakan melompat sehingga dengan melewati rintangan ini para pemain dapat melakukan atraksi melompat dan teknik keseimbangan sekaligus. Pada sisi-sisi bangunan terdapat rintangan-rintangan yang menyatu dengan bangunannya, sehingga bangunan tersebut bisa digunakan untuk atraksi, seperti halnya para trial bermain di bangunan-bangunan umum.

Terdapat ruang-ruang yang dimaksimalkan dengan pendekatan gerakan melompat dan keseimbangan pada tampilan luar maupun tampilan dalamnya dengan 
penggunaan penjorokan yang bebas. Karena penjorokan memiliki gaya yang berkesan selalu bergerak dan juga mengisyaratkan keseimbangan, penggunaan penjorokan ini sesuai dengan konsep Arsitektur Metafora seperti pada Gambar 4.

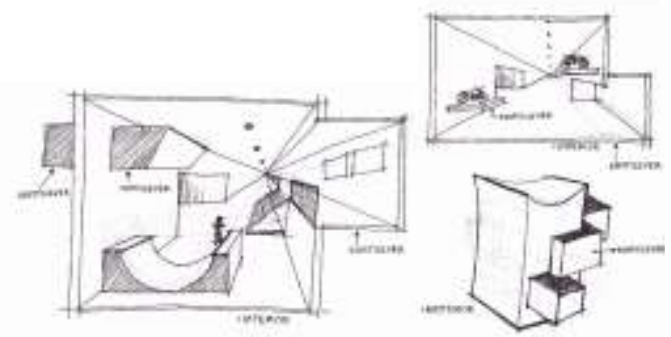

Gambar 4. Sketsa Penjorokan

\section{KESIMPULAN (KONSEP DESAIN)}

Dari hasil analisa serta hasil korelasi pada bagian sebelumnya, maka diperoleh hasil berupa desain Solo Trial Arena dengan pendekatan Arsitektur Metafora yang mengumpamakan sesuatu menjadi bentuk pada penampilan bangunan, tata ruang, maupun kawasannya sehingga dapat menciptakan bentuk bangunan yang kreatif, memicu adrenalin, dan atraktif. Bentuk tata masa dirancang metafora dari motor trial itu sendiri (lihat Gambar 5), sedangkan penerapan Arsitektur Metafora pada tampilan bangunan merupakan perubahan bentuk kotak dari suatu bentuk rintangan dalam trial baik di luar bangunan maupun di dalam bangunan (lihat Gambar 6 dan7).

Nama Arena : Solo Trial Arena

Lokasi : Jl. Lingkar Utara Surakarta

Luas Lahan : $30.052,45 \mathrm{~m}^{2}$

Luas Bangunan : $12.462,72 \mathrm{~m}^{2}$

Daya Tampung : 3.000 orang

Kegiatan : Petualangan motor

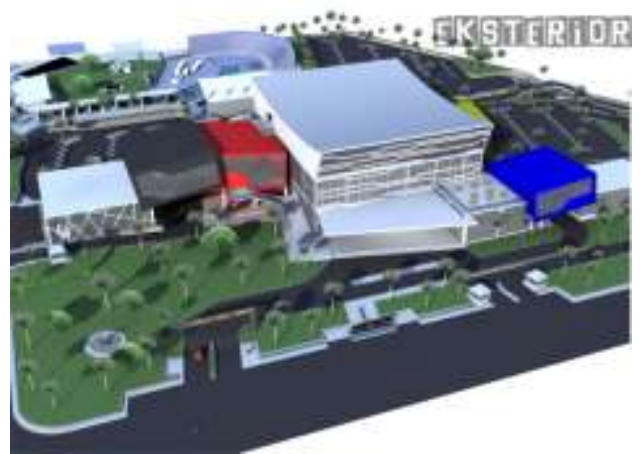

Gambar 5. Gambar Luar

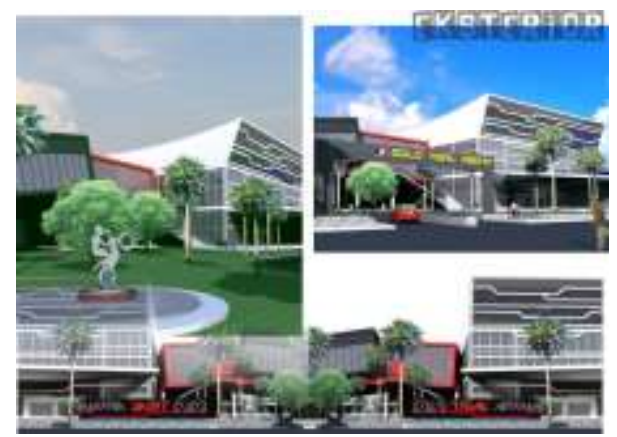

Gambar 6. Denah Lantai 1

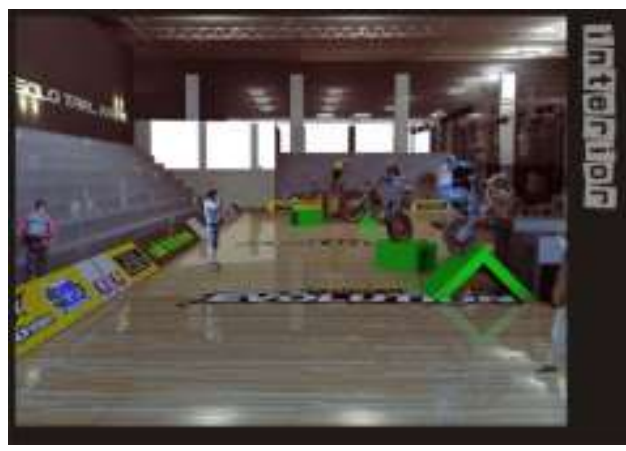

Gambar 7. Gambar Dalam Ruangan

\section{REFERENSI}

Sudarmanto, Bambang, 2008, Arsitektur dan Penggemar Karya Arsitektur.

Technology for stadium_structure.html

D.K. Ching, Francis, 1979, Arsitektur, Bentuk Ruang dan Susunannya

www.trials.com.au

www.trialscentral.com 